\title{
N-TERMINAL PRO-BRAIN NATRIURETIC PEPTIDE (NT-PROBNP) AS A BIOCHEMICAL MARKER FOR ASSESSING SEVERITY OF AORTIC STENOSIS
}

\author{
K. D. Singh1, Sanjeev Sharma ${ }^{2}$
}

${ }_{1}^{1}$ Assistant Professor, Department of Cardiology, S. S. Medical College, Rewa, Madhya Pradesh. ${ }^{2}$ Assistant Professor, Department of Radiodiagnosis, S. S. Medical College, Rewa, Madhya Pradesh.

ABSTRACT
BACKGROUND
Brain Natriuretic Peptide (BNP) is an endogenous cardiac hormone, mainly secreted from the ventricular myocardium. In
valvular heart diseases, either volume or pressure overload of the left ventricle occurs. Thus, it is reasonable to expect that NT-
proBNP might be useful in evaluating the severity and prognosis of valve diseases.

\section{AIMS}

Present study was done to evaluate the use of NT-proBNP to correlate the symptoms of AS with NT-proBNP level and to find out the correlation of NT-proBNP level with left ventricular functions.

\section{MATERIAL AND METHODS}

It was a randomized non-blinded study of 47 aortic stenosis patients. Echocardiographic evaluation including M-mode, 2D and Doppler echocardiography was done for all patients. NT-proBNP levels were measured in all the patients. On the basis of NTproBNP level, patients were grouped as Normal $(<60 \mathrm{pg} / \mathrm{mL})$, high $(60-3000 \mathrm{pg} / \mathrm{mL})$ and very high $(>300 \mathrm{pg} / \mathrm{mL})$.

\section{RESULTS}

Of the 47 patients, $37(78.72 \%)$ were males and the mean age of study group was $37.8 \pm 12.5$ years. There was a significant increase in NT-proBNP levels in aortic stenosis with LV dysfunction and increasing NYHA class.

\section{CONCLUSION}

BNP serum level may be useful for risk stratification in asymptomatic patients with severe aortic stenosis.

\section{KEYWORDS}

Aortic Stenosis, NT-proBNP, Valvular Heart Diseases.

HOW TO CITE THIS ARTICLE: Singh KD, Sharma S. N-terminal pro-brain natriuretic peptide (NT-proBNP) as a biochemical marker for assessing severity of aortic stenosis. J. Evolution Med. Dent. Sci. 2016;5(31):1673-1675, DOI: $10.14260 /$ jemds/2016/394

\section{INTRODUCTION}

Aortic Stenosis (AS) is most common valvular heart disease in developed countries. ${ }^{1}$ Symptomatic status and echocardiographic evaluation are the most important clinical tools used to confirm the diagnosis, assess severity and monitor advancement of AS.2 Aortic Valve Replacement (AVR) is usually indicated for symptomatic patients with severe AS, but whether asymptomatic patients should undergo AVR or should be treated conservatively is a question of debate. ${ }^{3} \mathrm{~N}$ Terminal-Pro-Brain Natriuretic Peptide (NT-proBNP) is neurohormones synthesized and secreted mainly by the ventricular myocardium. Its release is stimulated by an increase in ventricular wall stress. ${ }^{4}$ in patients with AS, NT-proBNP rise in correlation with severity and functional status as assessed by the New York Heart Association (NYHA) classification. 5

The present study was aimed to use the NT-pro-BNP to correlate symptoms of AS with NT-proBNP level and to find out the correlation of NT-proBNP level with LV functions.

Financial or Other, Competing Interest: None.

Submission 21-02-2016, Peer Review 22-03-2016,

Acceptance 28-03-2016, Published 18-04-2016.

Corresponding Author:

Dr. K. D. Singh,

E-8, Medical College Campus,

S. S. Medical College,

Rewa-486001,

Madhya Pradesh, India.

E-mail: doctor.sanjeev1976@gmail.com

DOI: $10.14260 /$ jemds/2016/394

\section{MATERIALS AND METHODS}

A randomized non-blinded study of 47 patients of predominant aortic stenosis with peak velocity of $\geq 2.5 \mathrm{~m} / \mathrm{s}$ was conducted in the Department of Medicine, S. S. Medical College, Rewa (M. P.), from January 2012 to February 2015. A written informed consent from all patients and Regional Ethics Committee approval was taken before starting study.

Patients with myocardial infarction within 6 months, regional wall motion abnormalities on echocardiography, prior cardiac surgery, more than mild mitral valve disease or aortic regurgitation, arterial fibrillation, significant comorbidities, serum creatinine level $>1.5 \mathrm{mg} / \mathrm{dL}$ and known severe respiratory disease (Forced expiratory volume in $1 \mathrm{~s}$ $<1 \mathrm{~L}$ ) were excluded from the current study.

In clinical assessment, patients were judged symptomatically if they had a history of symptoms of heart failure (NYHA class $\geq \mathrm{II}$ ) and/or angina (Canadian Cardiovascular Society class $\geq 1$ ) and/or exertional presyncope or syncope considered due to aortic stenosis and the information was recorded.

All patients underwent comprehensive echocardiographic evaluation including M-mode, 2D and Doppler echocardiography. Measurements were made according to American Society of Echocardiography Guidelines. The peak aortic velocity was recorded using continuous wave Doppler from the window yielding the highest velocity signal. The mean aortic valve gradient was obtained by tracing the continuous wave flow velocity signal across the aortic valve. Assessment of LV diastolic function 
was made from transmitral and pulmonary venous flow parameters and classified as normal, impaired relaxation, pseudonormal or restrictive.

Natriuretic peptide (NT-proBNP) level was measured quantitatively and grouped as Normal $(<60 \mathrm{pg} / \mathrm{mL})$, High (60-3000 pg/mL) and Very High $(>3000 \mathrm{pg} / \mathrm{mL})$. Statistical analysis was done using t-test and One Way ANOVA. Two Way ANOWA was used to compare the mean Natriuretic peptide levels within each NYHA class.

\section{RESULTS}

Of the 47 patients, $37(78.72 \%)$ were male and $10(21.27 \%)$ were female with mean age of $37.8 \pm 12.5$ years. The cause of aortic stenosis was rheumatic in 4 , bicuspid valve in 27 and degenerative calcification in 16 patients. Nine patients (19.2\%) were symptomatic and 38 (80.8\%) were asymptomatic. NT-proBNP level was correlated with peak aortic velocity $(\mathrm{r}=0.35)$, mean aortic gradient $(\mathrm{r}=0.37)$, LV mass index ( $\mathrm{r}=0.59)$, LV end-diastolic volume index $(\mathrm{r}=0.41)$, $\mathrm{LV}$ end-systolic volume index $(\mathrm{r}=0.54), \mathrm{LV}$ ejection fraction $(\mathrm{r}=-0.48)$, right ventricular systolic pressure $(\mathrm{r}=0.60)$, left atrial diameter $(\mathrm{r}=0.30)$ and $\mathrm{LV}$ end-diastolic posterior wall thickness ( $r=0.37$; $\mathrm{p}<0.05$ for all comparisons).

Natriuretic peptide levels were similar in patients with normal diastolic function ( $\mathrm{n}=16$; NT-proBNP: median, 168 pmol/L; interquartile range, 118 to $289 \mathrm{pmol} / \mathrm{L}$ ), an impaired relaxation pattern ( $\mathrm{n}=24$; NT-proBNP: median, $269 \mathrm{pmol} / \mathrm{L}$; interquartile range, 164 to $778 \mathrm{pmol} / \mathrm{L}$ ) or a pseudonormal pattern ( $\mathrm{n}=5$; NT-proBNP: median, $846 \mathrm{pmol} / \mathrm{L}$; interquartile range, 398 to $2867 \mathrm{pmol} / \mathrm{L}$ ). Natriuretic peptide levels were higher in 2 patients (All symptomatic) with restrictive diastolic dysfunction (median, $>3000 \mathrm{pmol} / \mathrm{L}$ ). All these patients had an LV ejection fraction $<40 \%$.

The symptomatic patients were older $(48 \pm 10$ years $)$ compared to asymptomatic $(35 \pm 15$ years $)$ patients $(p=0.035)$. The Natriuretic peptide levels and echocardiographic measures of asymptomatic and symptomatic patients are compared in Table 1.

There was a significant increase in NT-proBNP levels as the severity of aortic stenosis increased $(\mathrm{p}<0.0001)$. In a subanalysis of patients with an aortic valve area $\leq 1.0 \mathrm{~cm}^{2}(\mathrm{n}=29)$, the aortic valve area was similar in symptomatic $(n=9$; mean aortic valve area, $0.68 \pm 0.19 \mathrm{~cm}^{2}$ ) and asymptomatic patients $\left(\mathrm{n}=20\right.$; mean aortic valve area, $\left.0.76 \pm 0.12 \mathrm{~cm}^{2} ; \mathrm{p}=0.18\right)$.

NT-proBNP levels increased with increasing NYHA class. Within each NYHA class, Natriuretic peptide levels were not higher in patients with angina, presyncope or syncope than in those without these symptoms.

\begin{tabular}{|c|c|c|c|c|}
\hline Parameters & $\begin{array}{c}\text { Asymptomatic } \\
(n=38)\end{array}$ & $\begin{array}{c}\text { Symptomatic } \\
(n=9)\end{array}$ & t Statistic & $\mathbf{P}^{*}$ \\
\hline NT-proBNP (pmol/L) & 219 & 978 & 5.99 & $<0.0001$ \\
\hline Aortic valve area $\left(\mathrm{cm}^{2}\right)$ & $0.99 \pm 0.31$ & $0.71 \pm 0.23$ & 4.36 & $<0.0001$ \\
\hline Peak aortic velocity (m/s) & $4.0 \pm 0.8$ & $4.6 \pm 0.7$ & 3.81 & 0.0003 \\
\hline Mean aortic gradient (mmHg) & $39 \pm 16$ & $53 \pm 17$ & 3.58 & 0.0006 \\
\hline LV ejection fraction (\%) & $63 \pm 5.7$ & $41 \pm 11.6$ & 2.97 & 0.005 \\
\hline LV end-systolic volume index $\left(\mathrm{mL} / \mathrm{m}^{2}\right)$ & $18 \pm 6$ & $28 \pm 20$ & 2.54 & 0.02 \\
\hline LV mass index $\left(\mathrm{g} / \mathrm{m}^{2}\right)$ & $114 \pm 29$ & $137 \pm 35$ & 2.32 & 0.03 \\
\hline Posterior wall thickness in diastole (cm) & $1.10 \pm 0.22$ & $1.24 \pm 0.23$ & 2.25 & 0.03 \\
\hline Right ventricular systolic pressure (mmHg) & $28 \pm 6.1$ & $34 \pm 7.1$ & 2.28 & 0.03 \\
\hline $\mathrm{LV}$ end-diastolic volume index $\left(\mathrm{mL} / \mathrm{m}^{2}\right)$ & $53 \pm 11$ & $63 \pm 22$ & 2.16 & 0.04 \\
\hline \multicolumn{5}{|c|}{ Diastolic Function" } \\
\hline Normal Diastolic Function & $24(63)$ & $0(0)$ & & \\
\hline Impaired Relaxation & $10(26$ & $4(44)$ & & \\
\hline Pseudo Normal & $4(11)$ & $3(33)$ & & \\
\hline Restrictive Pattern & $0(0)$ & $2(22)$ & & 0.01 \\
\hline
\end{tabular}

NT-proBNP; N-Terminal Pro-Brain Natriuretic Peptide, LV; Left Ventricular, ${ }^{*} \mathrm{P}<0.05$ considered to be significant, \# Data are expressed as no. of patients (\%).

\section{DISCUSSION}

In present study, NT-proBNP level was higher in patients with NYHA class II symptoms than in those with class I symptoms, suggesting that NT-proBNP levels can be used to discriminate between early symptoms of heart failure and normal effort tolerance. Adjustment for NYHA class showed no association between Natriuretic peptide levels and syncope or the presence or absence of angina suggesting that the stimulus for increased secretion of Natriuretic peptides by cardiac myocytes is associated with the clinical manifestation and exertional dyspnoea.

In present study there was a progressive increase in Natriuretic peptide levels with decreasing aortic valve area, but a significant increase in Natriuretic peptide levels in patients with an ejection of $<40 \%$, emphasize the important association between LV systolic function and Natriuretic peptide level. Increased LV wall stress has been proposed as a stimulus for the release of Natriuretic peptide in aortic stenosis. ${ }^{4}$ Majority of the symptomatic patients in this study had normal diastolic function or an impaired relaxation pattern rather than more severe diastolic dysfunction.

The most widely used measures of aortic stenosis severity in clinical practice are the peak aortic velocity and the aortic valve area, as determined by the continuity equation. ${ }^{2}$ As in previous studies, these measures were most strongly associated with the presence of symptoms. ${ }^{6}$ Furthermore, NT-proBNP provided additional predictive value to the aortic valve area and LV ejection fraction for the presence of symptoms. 
Previous studies have shown that Natriuretic peptide levels increase with normal aging and are higher in women than in men with no cardiac disease suggesting the use of age and sex specific normal range would improve the diagnostic accuracy of Natriuretic peptide levels. ${ }^{7}$ In current study, the association between Natriuretic peptide levels and symptoms did not increase after adjustment for age. The possible explanation is that Natriuretic peptide levels reflects age related changes in myocardial function. ${ }^{8}$

The association between NT-proBNP level and symptoms was stronger in men than in women. In previous studies, women have had greater impairment of functional status and a poorer exercise capacity than men, despite a similar aortic valve area and greater LV functional shortening. 9

As in clinical practice it is likely that some patient's symptoms were not a consequence of aortic stenosis, whereas other were classified as asymptomatic because they undertook little physical activity or ignored subtle symptoms. Exercise testing has been proposed as a method of identifying patients with aortic stenosis who are at increased risk. ${ }^{10}$

This study has its limitation because of small sample size, to draw any definite conclusion. Further large prospective studies are needed to determine whether serial measurement of Natriuretic peptide levels can be used to monitor disease progression and predict clinical outcome and whether high Natriuretic peptide levels should be an indication for surgery in apparently asymptomatic patients.

\section{CONCLUSION}

BNP serum level may be useful for risk stratification in asymptomatic patients with severe aortic stenosis. Asymptomatic patients with aortic stenosis who have NTproBNP levels above the normal range are at higher risk of symptomatic deterioration than patients with NT-proBNP levels in the normal range. Plasma NT-proBNP levels are elevated in symptomatic patients with aortic stenosis.

\section{REFERENCES}

1. Jordi Soler-Soler, Enrique Galve. Valve disease: worldwide perspective of valve disease. Heart 2000;83(6):721-5.

2. Neelakantan Saikrishnan, Gautam Kumar, Fadi J Sawaya, et al. Accurate assessment of aortic stenosis: a review of diagnostic modalities and hemodynamics. Circulation 2014;129:244-53.

3. Nishimura RA, Otto CM, Bonow RO, et al. 2014 AHA/ACC guidline for the management of patients with valvular heart disease. JACC 2014;63(22):e57-e185.

4. Bergler-Klein. Natriuretic peptides in the management of aortic stenosisi. J Curr Cardiol Rep 2009;11(2):85-93.

5. Lim P, Monin JL, Monchi M, et al. Predictors of outcomme in severe aortic stenosis with normal left ventricular function: role of B-type natriuretic peptide. Eur Heart J 2004;25:2048-53.

6. Gerber IL, Stewart RA, Legget ME, et al. Increased plasma natriuretic peptide levels reflect symptom onset in aortic stenosis. Circulation 2003;107(14):1884-90.

7. Redfield MM, Rodeheffer RJ, Jacobsen SJ, et al. Plasma brain natriuretic peptide concentration: impact of age and gender. J Am Coll Cardiol 2002;40(5):976-82.

8. Di Angelantonio E, Chowdhury R, Sarwar N, et al. B-type natriuretic peptides and cardiovascular risk: systematic review and meta-analysis of 40 prospective studies. Circulation 2009;120(22):2177-87.

9. Fuchs C, Mascherbauer J, Rosenhek R, et al. Gender differences in clinical presentation and surgical outcome of aortic stenosis. Heart 2010;96(7):539-45.

10. Julien Magne, Patrizio Lancellotti, Luc A Piérard, et al. Exercise testing in asymptomatic severe aortic stenosis. J Am Coll Cardiol Img 2014;7(2):188-99. 